\title{
Stillbirths: A high magnitude public health issue in India
}

\author{
Divya K Bhati
}

Research Scholar, Institute of Health Management Research, Jaipur, India.

\begin{abstract}
A stillbirth is a baby born with no signs of life at or after 28 weeks' gestation, while preterm births are those which occur between 28 weeks to 32 weeks of gestation. Approximately 3.2 million stillbirths occur annually in low- and middle-income countries. The aim of this paper is to review the present status of the stillbirths and identify the underlying factors of stillbirths in India. A search of PubMed and other search engines were conducted to retrieve the literature pertaining to neonatal and perinatal health in India. Four priority areas were used to select the studies: overview (prevalence of the stillbirths), challenges in mapping the potential causes of stillbirths, socio-cultural factors associated with stillbirths, and government response towards stillbirths. It was found that women face many difficulties due to accessibility, availability, affordability and quality issues when utilizing healthcare facilities during pregnancy. Several studies based on stillbirths also revealed the social aspects of perinatal grief. Stillbirths are bounded by high family pressures and social stigma. A review also revealed that half of all stillbirths occur in India, Pakistan, Nigeria, China and Bangladesh alone. These countries also account for a high number of maternal and newborn deaths. India has highest number of stillbirths in the world - the rates range from 20 to 66 per 1000 births in different states. It was also found that healthcare and socio-cultural factors contribute to the increase in the number of stillbirths in India. These issues highlight the need for urgent action and interventions to be taken by the government and other organization to improve the situation of stillbirths in India. Early neonatal deaths and stillbirths usually have obstetric causes, and are largely preventable if good quality obstetric care is made available at the right time. Initiatives for strengthening the information management system at the grassroots level to report stillbirths on a regular basis are necessary to improve the neonatal health indicators in India.
\end{abstract}

Keywords: Stillbirths, Neonatal mortality, Socio-economic factors, Reporting system, India.

\section{Introduction}

A stillbirth is a baby born with no signs of life at or after 28 weeks' gestation while preterm births are those which occur between 28 weeks to 32 weeks of gestation. ${ }^{1}$ There were over 2.6 million stillbirths globally in 2009 and $98 \%$ occurred in low- and middle-income countries. ${ }^{2}$ In 2009, $76.2 \%$ of stillbirths occurred in South Asia and SubSaharan Africa. ${ }^{2}$ Though most stillbirths are avoidable, surprisingly the issue is overlooked and neglected in developing countries like India. ${ }^{2}$ A quarter of world's neonatal deaths (one million) each year take place in India, ${ }^{3}$ mostly at home $(65.4 \%$ of all births and $75.3 \%$ of births in rural areas occur at home). ${ }^{4}$ Child healthcare is a matter of concern in India. The issues in relation to Child healthcare have been addressed by the Government since 1975 through the Integrated Child Development Scheme (ICDS) and which is the largest scheme for children under six years of age. ${ }^{5}$ A review conducted by Rajaratnam et $a l .{ }^{6}$ on neonatal, post neonatal, and under-5 mortality identified the neonatal mortality rate (NMR) of 34 of 1000 live births and a declining but still high stillbirth rate of 27 of 1000 births in India. India is not yet on target to achieve its Millennium Development Goal (MDG) 4, with annual stillbirth and neonatal deaths at over 1 million. ${ }^{6}$ Unfortunately, each year, 10.6 million children die and this number goes uncounted across the world. ${ }^{7}$ Among

\section{Practice Points}

- India has highest number of stillbirths in the world - the rates range from 20 to 66 per 1000 births in different states.

- Socio-cultural factors, misconceptions and taboos have strong influence on child mortality including stillbirths.

- It was found that women face many difficulties due to accessibility, availability, affordability and quality issues when utilizing healthcare facilities during pregnancy.

- Early neonatal deaths and stillbirths usually have obstetric causes and largely preventable if good quality obstetric care is made available at the right time.

- To capture the true number of stillbirths and make them visible it is necessary to have powerful reporting systems in place.

Correspondence: Divya K Bhati, Research Scholar, Institute of Health Management Research (IHMR), 1 Prabhu Dayal Marg, Jaipur-302011, India. E-mail: bhatidivyak@gmail.com. 
these 3.2 million annual stillbirths occur in low- and middle-income countries. ${ }^{8}$ India has highest number of stillbirths in the world. According to Lawn et al., ${ }^{9} 66 \%$ (1.8 million) stillbirths in the world occur in just 10 countries: India, Pakistan, Nigeria, China, Bangladesh, Democratic Republic of the Congo, Ethiopia, Indonesia, Afghanistan and the United Republic of Tanzania. In India, the stillbirth rates varied from 20 to 66 per 1,000 total births in different States. ${ }^{9}$

The aim of this paper is to review the situation and factors of stillbirths in India. A search of PubMed and other search engines were conducted to retrieve the literature pertaining to neonatal and perinatal health. Four priority areas were used to include the studies: overview (prevalence of the stillbirths), challenges in mapping the potential causes of stillbirths, socio-cultural factors associated with stillbirths, and government response towards stillbirths. The definitions of key terms related to stillbirths are included in Box 1.

\section{Counting stillbirths: An overview}

Safe motherhood and child survival have always been a concern for the policy makers but perinatal mortality, especially stillbirths, have not received due attention. ${ }^{11}$ Although an estimated 10.6 million children aged 0 to 5 die each year, national health information systems across the globe fail to count most child deaths. ${ }^{12}$ Stillbirths are invisible in many societies and ignored not counting on policy, program, and investment and often also at the national level. ${ }^{13}$ Inconsistent use of terminology has contributed to confusion about stillbirths. ${ }^{13}$ The terminology has changed over time and, despite clear worldwide guidelines, there is much variation between countries, with greater variability in high-income countries than in low-income countries. ${ }^{14,15}$ According to World Health Organization, 'A stillbirth refers to a dead born fetus which can either occur before the onset of labor (ante-partum death) or during labor (intra-partum death) and is expressed per 1000 of total births'. ${ }^{16}$ Eliciting pregnancy and birth history during populationbased surveys also run the risk of being incomplete and tend to suffer from recall biases, especially related to the exact timing of death. ${ }^{17}$ As long as countries do not prioritize perinatal health issues and design monitoring systems that capture both antepartum and intra-partum stillbirths, the reporting of stillbirths will remain weak. As per the WHO 2007 Report, capturing the timing of death of the unborn babies would help us formulate effective interventions to address the high rates of stillbirth and early neonatal mortality. ${ }^{18}$ Prior to 2006 , no organization had published global, regional or countryspecific stillbirth rates. Two global series of stillbirth estimates for the year 2000 were published in 2006 (here after referred to as the SNL/immpact and WHO estimates). ${ }^{19,20}$ It has been indicated that there are substantial differences of data at the country level. ${ }^{20}$

The lowest stillbirth rates outside of the developed world were in Eurasia, Southeast Asia, and Latin America and the Caribbean $(12,13$, and 13 per 1,000 respectively). ${ }^{21}$ As per Fig. 1, India shares the highest burden of stillbirths $(75 \%)$ as compared to other South-East Asian countries. ${ }^{22}$ To capture stillbirth events in India, it is very important to consider that these births occur at home, health centers, medical institutions and hospitals. Table 1 shows rural-urban distribution of stillbirth rates in different states of India for the year $2010 .^{23}$ The stillbirth rate is estimated as the ratio of the number of stillbirths per 1000 live births and stillbirths during the year. ${ }^{23}$ At the national level in India, the estimate of stillbirth rate for the year 2010 is 7 . Among the bigger states, the highest level of stillbirth rate has been estimated for Karnataka (14) and the lowest for Bihar and Jharkhand (1). Stillbirths are extremely difficult to capture and there is a room for considerable improvement in netting the events. ${ }^{23}$

\section{Causes of neonatal mortality}

More than 30 different stillbirth classification systems have been identified in the literature, ${ }^{24}$ with some encompassing up to 37 causes. ${ }^{25}$ Early neonatal deaths and stillbirths usually have obstetric causes and are largely preventable if good quality obstetric care is made available at the right time. ${ }^{26}$ Globally, the main causes of neonatal deaths are thought to be preterm birth (28\%), pneumonia $(26 \%)$ and birth asphyxia $(23 \%){ }^{27,28}$ In the South Asia Region, $52 \%$ of child mortality is due to preterm births $(19 \%)$, sepsis or pneumonia $(22 \%)$, intra partum complications and to diarrhoea (10\%),

Box 1: Definitions of key terms related to stillbirths ${ }^{10}$

Fetal death: The International Classification of Diseases, Revision 10 (ICD-10) defines a fetal death as 'death prior to the complete expulsion or extraction from its mother of a product of conception, irrespective of the duration of pregnancy; the death is indicated by the fact that after such separation the fetus does not breathe or show any other evidence of life, such as beating of the heart, pulsation of the umbilical cord, or definite movement of voluntary muscles' without specification of the duration of pregnancy.

Early fetal deaths: According to the ICD-10, an early fetal death is death to a fetus weighing at least 500 grams (or, if birth weight is unavailable, after 22 completed weeks gestation, or with a crown-heel length of 25 centimeters or more)

Late fetal deaths (stillbirths): A late fetal death is defined as a fetal death weighing at least 1000 grams (or a gestational age of 28 completed weeks or a crown-heel length of 35 centimeters or more). The ICD-10 recommends this definition for the purposes of international comparison. 


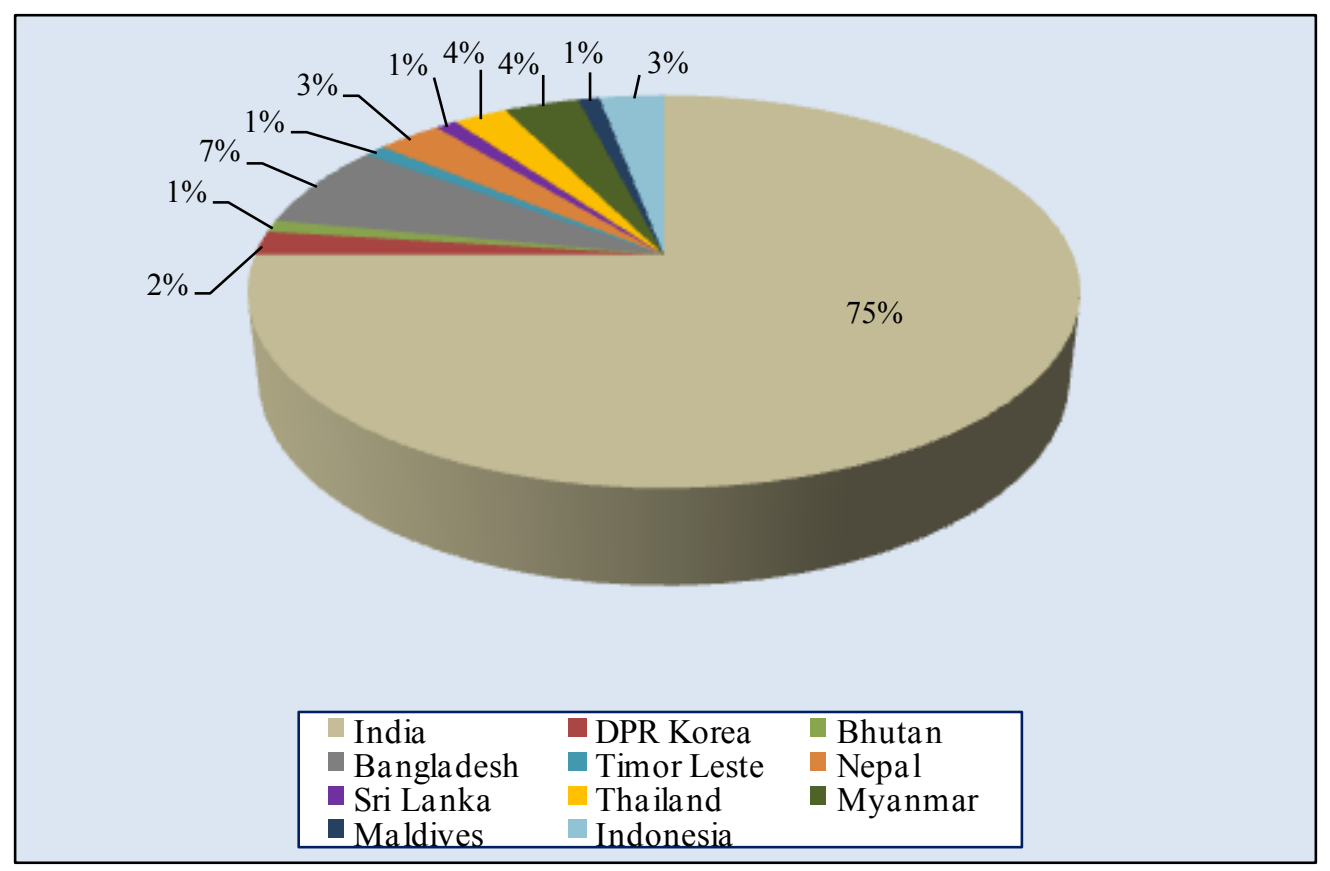

Figure 1: Burden of stillbirths in South-East Asia ${ }^{22}$

congenital abnormalities (5\%), tetanus $(2 \%)$ and other causes (13\%) (Fig 2). ${ }^{29}$ Stillbirths are yet to be counted in global and national statistics or in health policy. ${ }^{30}$ Even when the stillbirths are recorded in surveys, the data is frequently combined with early neonatal deaths and reported as perinatal mortality, a combination that reduces visibility and might mask reporting differences. ${ }^{30}$ Stillbirths are a significant indicator in determining the disease burden for mother and child. ${ }^{31}$ Indirect causal pathways are environmental and social and cultural factors. Environmental factors include deficient infrastructure which contributes to a lack of women receiving antenatal care, ${ }^{32}$ cooking with bio-mass fuel ${ }^{33}$ and poverty. ${ }^{34}$ Effective reporting and lowering the prevalence of stillbirths will improve maternal and child health. All countries need sound epidemiological information to prioritize, plan, and implement public health interventions. ${ }^{35}$ Vital event registration that includes cause of death data is used to establish the cause structure of mortality. India and China have attempted to establish sample registration systems, but it is not yet clear whether they are truly representative and correctly classify causes of child deaths. ${ }^{36}$

Table 1: Stillbirth rates in some selected states of India, $2010^{23}$

\begin{tabular}{|l|c|c|c|}
\hline \multirow{2}{*}{ India/states } & \multicolumn{3}{c|}{ Stillbirth rate } \\
\cline { 2 - 4 } & Total & Rural & Urban \\
\hline India & 7 & 7 & 7 \\
\hline Andhra Pradesh & 7 & 8 & 5 \\
\hline Assam & 9 & 9 & 1 \\
\hline Bihar & 1 & 1 & 7 \\
\hline Chhattisgarh & 12 & 13 & 7 \\
\hline Delhi & 6 & 3 & 9 \\
\hline Gujarat & 8 & 7 & 7 \\
\hline Haryana & 9 & 10 & 3 \\
\hline Himachal Pradesh & 10 & 11 & 8 \\
\hline Jammu and Kashmir & 5 & 5 & 1 \\
\hline Jharkhand & 1 & 2 & 12 \\
\hline Karnataka & 14 & 16 & 5 \\
\hline Kerala & 7 & 7 & 10 \\
\hline Madhya Pradesh & 8 & 7 & 10 \\
\hline Maharashtra & 7 & 5 & 11 \\
\hline Odisha & 8 & 8 & 6 \\
\hline Punjab & 6 & 6 & 5 \\
\hline Rajasthan & 6 & 6 & 5 \\
\hline Tamil Nadu & 10 & 14 & 5 \\
\hline Uttar Pradesh & 5 & 6 & 5 \\
\hline West Bengal & 9 & 10 & \\
\hline
\end{tabular}




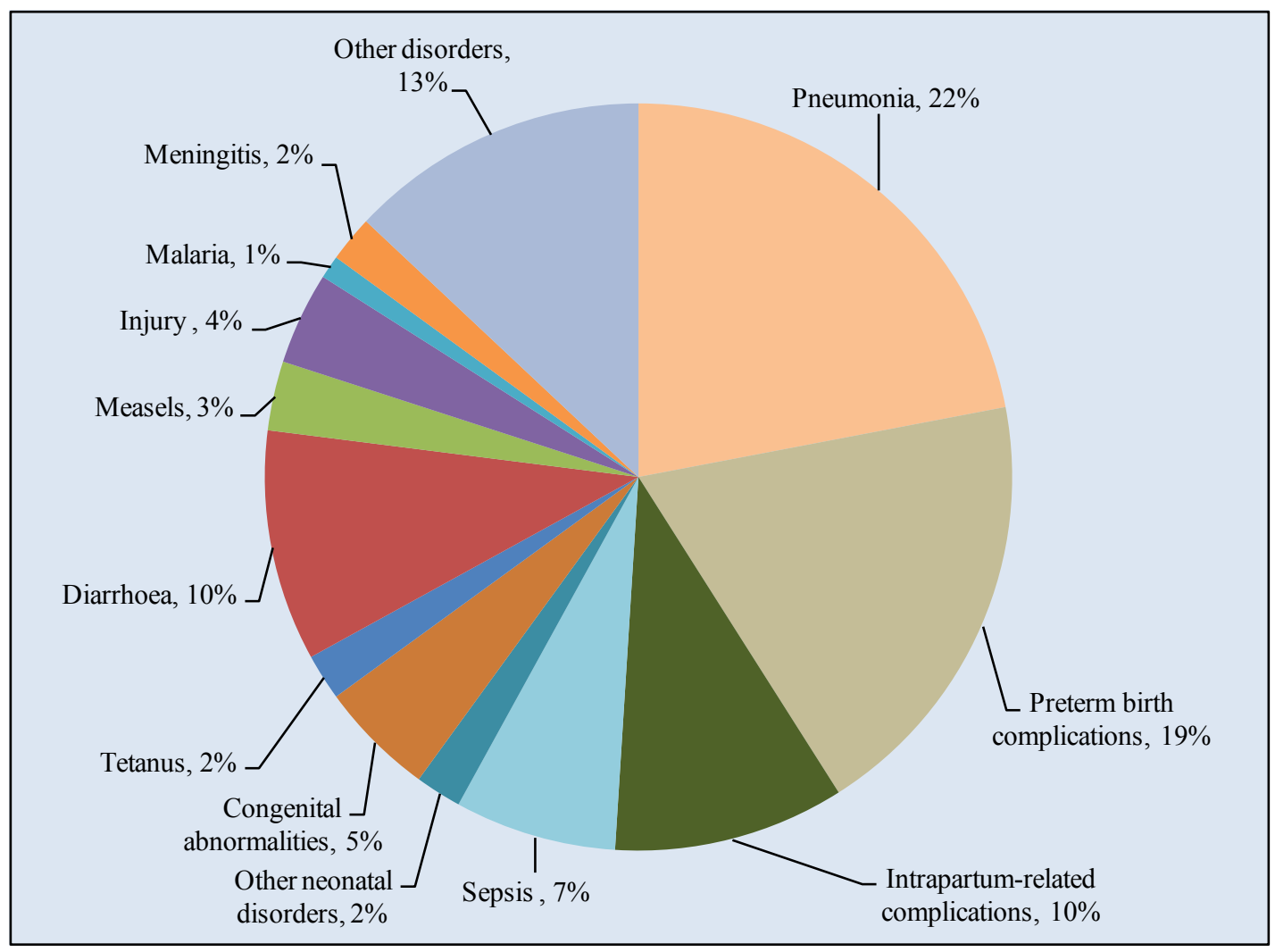

Figure 2: Causes of child mortality- South $\mathrm{Asia}^{29}$

\section{Stillbirths: Underlying issues}

Stillbirths are invisible at policy level partly because they are frequently invisible at the societal level. ${ }^{37}$ Social taboos mean that open mourning, public discussion and also media coverage is rare, and this affects the policy priority given to stillbirths by the media and by politicians. ${ }^{37}$ Perinatal losses have also been shown to have a substantial psychological impact on parents and families, and are associated with post-traumatic stress, depression, anxiety, and sleeping disorders. ${ }^{38,39}$ India with 1700 heterogeneous cultures, in different linguistic regions, has difficulties in implementation, utilization and functioning of government healthcare programs. ${ }^{40}$ The cultural beliefs operate through diverse socioeconomic and income-related factors which have strong influence on child mortality, starting from the mother's womb and continues through the neonatal, post neonatal period and persists throughout the life cycle. ${ }^{40}$ In low-income countries, stillbirths remain a largely hidden phenomenon, as they often occur at home, fetal remains are buried without ceremony, and families rarely mourn publicly. Wherever pregnancy loss and child death are common, pregnancy and childbirth are seen as rendering women and their babies highly vulnerable to harm from disease, malevolent individuals, or spiritual forces, often until well into the postnatal period. ${ }^{41}$ Women's risk of being stigmatized further suppresses women's willingness or ability to discuss a stillbirth publicly, particularly if the stillbirth may be misconstrued as induced abortion ${ }^{42}$ or is associated with childlessness. ${ }^{43,44}$ A stillbirth hampers every aspect of women's wellbeing i.e. social, cultural, emotional and psychological. Mullan et $a l^{45}$ describe consequence of a stillbirth as: 'The grief of a stillbirth is unlike any other form of grief: the months of excitement and expectation, planning, eager questions and the drama of labor - all magnifying the devastating incomprehension of giving birth to a baby bearing no signs of life.' There key cultural misconceptions of stillbirths as highlighted by Sather et al. ${ }^{46}$ include nature's way of intervening when a baby is stillborn and stillbirth is perceived as the mother's fault - which lead to feelings of shame and remorse for women. The loss is tremendous and irreversible, the mother is in deep distress, and can't hold the baby in her hands and does not even perform the rituals. ${ }^{46}$ After nurturing for long nine months it is like the hands are empty with great loss. ${ }^{46}$ The prime driver of improvement in India is cultural aspects health education strategies based on selective adoption of indigenous concerns can go a long way in improving health of mother and child. 'By shining a spotlight on the tragic toll of stillbirths, we can prevent stigma, relieve suffering and make greater progress to improve the health of every woman and every newborn. ${ }^{47}$

\section{Governance and its response to still- births}

Assessing the impact and magnitude of stillbirth is an important lap of the hurdle in creating a successful advocacy roadmap. To capture the true number of stillbirths and make them visible it is necessary to have powerful reporting systems in place. The integrated use 
of health informatics is slowly developing for better human resource management, GIS applications, mobile health, maintaining patient information in hospitals, nutrition and disease surveillance systems, death reporting, case-based follow-up systems including systematic pregnancy and child tracking in different parts of India. ${ }^{48}$ In Dahanu, India, the stillbirth rate dropped from $18.6 \%$ to $9 \%$ over a three-year period with introduction of a traditional birth attendant training programme in which neonatal resuscitation was a central component. ${ }^{49}$ A novel approach i.e. National Rural Health Mission (NRHM) launched by the Government of India to provide healthcare and advance institutional deliveries to people living in the rural areas leads to reduced number of perinatal mortality. ${ }^{50}$ The data on stillbirths is also important to draw an action plan and eliminate the contributing factors. The Health Management Information System (HMIS) - a web based portal launched in October 2008 is envisaged as a 'single-window' for all public health data, for Ministry of Health and Family Welfare. ${ }^{51}$ Strategic investments are required so that every mother and newborn whether alive or stillborn is accounted for within the system. ${ }^{52}$ This information is essential for critically assessing program performance, perform adjustments and support program implementation. $^{52}$ Mother and Child Tracking System (MCTS) jointly developed by the Ministry of Health and Family Welfare and National Informatics Centre, launched by the Government of India in 2009 in collaboration with the states. ${ }^{53}$ MCTS serves as an important tool to capture the health of both mother and child at national level. ${ }^{53}$ The tracking system gives multiple dimensions to the mother and child's health and facilitates the service providers at the grass root levels i.e. information related to pregnant women is being entered in MCTS from 139,551 (84\%) sub-centers, 22,558 (79\%) health facilities other than sub-centers. More than 1.77 core pregnant women and 1.20 core children have been registered in the system since its inception. In this way, the system contributes towards universal access to healthcare services for pregnant women and children, and keeps track of maternal mortality and perinatal mortality including stillbirths. ${ }^{53}$

\section{Conclusion}

India shares a high burden of stillbirths with priority gaps in reporting and recognizing at the health policy level. It is evident from the literature that stillbirths do not get adequate attention in the health system and they are not recognized as a public health issue. Entangled within socio-cultural misconceptions, stillbirths lose out on medical care. Mother and Child Tracking System in India is contributing towards universal access of all pregnant women and children to maternal and child health services and thereby accelerating reduction in mother and infant mortality. We cannot eliminate all stillbirths but driving uniformity in reporting of stillbirths through research can sensitize the community, health program managers and policy makers. Better counting of stillbirths and improved cause-of-death data can advocate child survival strategies. Global groups working on child health can actively promote system- atic, peer-reviewed and well-documented estimates of stillbirths. This well-documented data will definitely help to chart actions to improve child health and survival.

\section{References}

1. World Health Organization. Stillbirths. http:// www.who.int/maternal child adolescent/ epidemiology/stillbirth/en/ (accessed June 2013)

2. Cousens S, Blencowe H, Stanton C, Chou D, Ahmed S, Steinhardt L et al. National, regional, and worldwide estimates of stillbirth rates in 2009 with trends since 1995: a systematic analysis. Lancet 2011; 377(9774):1319-30.

3. United Nation Children's Fund (UNICEF). The State of the World's children 2008. Child Survival. UNICEF, 2008.

4. International Institute of Population Sciences and Macro International. National Family Health Survey (NFHS-3), 2005-06: India. Volume 1. Mumbai: IIPS, 2007.

5. Trivedi S, Chapparwal BC, Thora S. Utilization of ICDS Scheme in Children one to six years of age in a rural block of Central India. Indian Pediatr 1995;32:47-50.

6. Rajaratnam JK, Marcus JR, Flaxman AD, Wang H, Levin-Rector A, Dwyer L, et al. Neonatal, post neonatal, childhood, and under-5 mortality for 187 countries, 1970-2010: a systematic analysis of progress towards Millennium Development Goal 4. Lancet 2010; 375(9730):1988-2008.

7. Stanton C, Lawn JE, Rahman H, WilczynskaKetende K, Hill K. Stillbirth rates: delivering estimates in 190 countries. Lancet 2006; 367 (9521):1487-8.

8. Yakoob MY, Menezes EV, Soomro T, Haws RA, Darmstadt GL, Bhutta ZA. Reducing stillbirths: behavioural and nutritional interventions before and during pregnancy. BMC Pregnancy Childbirth 2009; 9(Suppl 1):S3.

9. Lawn JE, Lawn JE, Blencowe H, Pattinson R, Cousens S, Kumar R et al. Stillbirths: Where? When? Why? How to make the data count? Lancet 2011; 377:1448-63.

10. World Health Organization. ICD-10 International Statistical Classification of Diseases and Related Health Problems: Tenth revision. Volume 2. Instruction manual. Geneva: WHO, 1993.

11. Lawn JE, Gravett MG, Nunes TM, Rubens CE, Stanton C, the GAPPS Review Group. Global report on preterm birth and stillbirth (1 of 7): definitions, description of the burden and opportunities to improve data. BMC Pregnancy Childbirth 2010 ;(Suppl 1):S1,1471-2393.

12. Immpact Population Reference Bureau Factsheet. Evaluating Stillbirths: Improving stillbirth 
data could help make stillbirths a visible public health policy. University of Aberdeen, Population Reference Bureau (PRB), United Kingdom, 2007.

13. Froen JF, Cacciatore J, McClure EM, Kuti O, Jokhio AH, Islam M, et al. Stillbirths: why they matter. Lancet 2011; 377:1353-66.

14. Woods R. Long-term trends in fetal mortality: implications for developing countries. Bull World Health Organ 2008; 86: 460-66.

15. Woods R. Death before birth: Fetal Health and Mortality in Historical Perspective. New York: Oxford University Press, 2009.

16. World Health Organization (WHO). Neonatal and perinatal mortality, country, regional and global estimated. Department of Making Pregnancy safer. Geneva: WHO, 2004.

17. Harter L, Starzyk P, Frost F. A comparative study of hospital fetal death records and Washington State fetal death certificates. Am. J .Public Health 1986; 76: 1333-4.

18. World Health Organization. Everybody's business: Strengthening health systems to improve health outcomes: WHO's framework for action. Geneva: WHO, 2007.

19. Howson CP, Kinney MV, Lawn JE. March of Dimes, PMNCH, Save the Children, WHO. Born Too Soon: The Global Action Report on Preterm Birth. Eds. World Health Organization. Geneva, 2012.

20. World Health Organization (WHO). Perinatal and neonatal mortality for the year 2000: Country, regional and global estimates. Geneva, 2006.

21. Singh SK, Kaur R, Gupta M, Kumar R. Impact of national rural health mission on perinatal mortality in rural India. Indian Pediatrics 2012; 49: $136-8$.

22. World Health Organization, Global database on births attended by skilled health personnel. Geneva: WHO, 2009.

23. Census of India. Estimates of mortality indicators 2010. http://www.censusindia.gov.in/ vital statistics/srs/Chap 4 2010.pdf (accessed June 2013)

24. Korteweg FJ, Gordijn SJ, Timmer A, Erwich JJ, Bergman KA, Bouman K, et al. The Tulip classification of perinatal mortality: introduction and multidisciplinary inter-rater agreement. BJOG 2006; 113(4):393-401.

25. Gardosi J, Kady SM, McGeown P, Francis A, Tonks A. Classification of stillbirth by relevant condition at death (ReCoDe): population based cohort study. BMJ 2005; 331(7525):1113-7.

26. Zadkarami MR. Risk factors for perinatal mortality: Random effect model. Asian J Epidemiol
2008; 1: 53-63.

27. Lawn JE, Cousens S, Zupan J. 4 million neonatal deaths: When? Where? Why? Lancet 2005; 365 : 891-900.

28. Bryce J, Boschi-Pinto C, Shibuya K, Black RE. World Health Organization (WHO) estimates of the causes of death in children of death in children. Lancet 2005; 365:1147-52.

29. Liu L, Johnson H, Cousens S, Perin J, Scott S, Lawn JE et al. Global, regional, and national causes of child mortality: an updated systematic analysis for 2010 with time trends since 2000 . Lancet 2012; 379: 9832:2151-61.

30. Goldenberg RL, McClure EM, Bhutta ZA, Belizan JM, Reddy UM, Rubens CE et al. Stillbirths: the vision for 2020. Lancet 2011; 377 (9779):1798-805.

31. Kelley M, Rubens CE , the GAPPS Review Group. Global report on preterm birth and stillbirth (6 of 7) ethical considerations. BMC Pregnancy Childbirth 2010;10 (Suppl 1):S6.

32. Di Mario S, Say L, Lincetto O. Risk factors for stillbirth in developing countries: A systematic review of the literature. Sex Transm Dis 2007; 34 (7), S11-S21.

33. Mishra V, Retherford RD, Smith K.R. Cooking smoke and tobacco smoke as risk factors for stillbirth. Int J Environ Health Res 2005; 15(6):397410 .

34. Lawn JE, Kinney M, Lee AC, Chopra M, Donnay F, Paul VK et al. Reducing intrapartumrelated deaths and disability: can the health system deliver? Int J Gynecol Obstet 2009; 107:S123-S42.

35. Black RE, Morris SS, Bryce J. Where and why are 10 million children dying every year? Lancet 2003; 361: 2226-34.

36. Lopez AD, Ahmad OB, Guillot M, Inoue $\mathrm{M}$, Ferguson BD, Salomon JA. Life tables for 191 countries for 2000: data, methods, results. GPE discussion paper number 40. Geneva: World Health Organization, 2001.

37. Lawn JE, Yakoob MY, Haws RA, Soomro T, Darmstadt GL, Bhutta ZA. 3.2 million stillbirths: epidemiology and overview of the evidence flow. BMC Pregnancy Childbirth 2009; 9(Suppl 1):S2, 1471:2393-9.

38. Hughes P, Riches S. Psychological aspects of perinatal loss. Curr Opin Obstet Gynecol 2003; 15:107-11.

39. Boyle FM, Vance JC, Najman JM, Thearle MJ. The mental health impact of stillbirth, neonatal death or SIDS: prevalence and patterns of distress among mothers. Soc Sci Med 1996; 43:1273 -82 .

40. Ghosh R. Child mortality in India: a complex 
situation, World J Pediatr 2012; 8(1):11-8.

41. Winch PJ, Alam MA, Akther A, Afroz D, Ali NA, Ellis AA et al. Local understandings of vulnerability and protection during the neonatal period in Sylhet District, Bangladesh: a qualitative study. Lancet 2005; 366(9484):478-85.

42. Erviti J, Castro R, Collado A. Strategies used by low-income Mexican women to deal with miscarriage and "spontaneous" abortion. Qual Health Res 2004; 14(8):1058-76.

43. Stewart DE, Stotland NL, (Eds). Psychological Aspects of Women's Health Care: The Interface between Psychiatry and Obstetrics and Gynecology. Washington DC: American Psychiatric Press, 1993.

44. Savage OMN. Children of the Rope and Other Aspects of Pregnancy Loss in Cameroon. In: Cecil R (Ed). The Anthropology of Pregnancy Loss: Comparative Studies in Miscarriage, Stillbirth, and Neonatal Death. Oxford: Berg, 1996.

45. Mullan Z, Horton R. Bringing stillbirths out of the shadows. Lancet 2011; 377: 9774:1291-2.

46. Sather M, Fajon AV, Zaentz R, Ruben CE, the GAPPS Review Group. Global report on preterm birth and stillbirth (5 of 7): advocacy barriers and opportunities. BMC Pregnancy Childbirth 2010; 10(Suppl 1):S5.
47. Partnership for Maternal, Newborn and Child Health. Stillbirths: The Invisible Public Health Problem. Science Daily, April 14, 2011. http:// w w w. s c i e n c e d a i l y. c o m / releases/2011/04/110411384958.htm (accessed June 2013)

48. Ministry of Health and Family Welfare. A Strategic Approach to Reproductive, Maternal, Newborn, Child and Adolescent Health $(\mathrm{RMCH}+\mathrm{A})$ in India. New Delhi: Ministry of Health and Family Welfare, 2013.

49. Daga SR, Daga AS, Dighole RV, Patil RP, Dhinde HL. Rural neonatal care: Dahanu experience. Indian Pediatr 1992;29:189-93.

50. Ngoc NT, Merialdi M, Aleem HA, Carroli G, Purmar M, Zavaleta N, et al. Causes of stillbirths and early neonatal death, data from 7993 pregnancies in six developing countries. Bull World Health Organ 2006; 84:699-705.

51. National Institute of Health and Family Welfare. Introductory Document: Capacity Building to Improve Data Quality under HMIS and MCTS Portals. New Delhi: NIHFW, 2008.

52. Sharma G. Maternal, Perinatal and Neonatal Mortality in South-East Asia. Asian J Epidemiol 2011;1-14.

53. Kumar S, Bhatnagar S, Saxena M. Mother and Child Tracking System. Lead Story. Informatics 2012;20(4):4-8. 